\title{
Trends in energy and macronutrient intakes by weight status over four decades
}

\author{
William S Yancy $\mathrm{Jr}^{1,2, *}$, Chi-Chuan Wang ${ }^{3}$ and Matthew L Maciejewski ${ }^{1,2}$ \\ ${ }^{1}$ Center for Health Services Research in Primary Care, Department of Veterans Affairs, HSR\&D (152), \\ VA Medical Center, 508 Fulton Street, Durham, NC 27705, USA: ${ }^{2}$ Division of General Internal Medicine, \\ Department of Medicine, Duke University Medical Center, Durham, NC, USA: ${ }^{3}$ Research Triangle Institute, \\ Research Triangle Park, NC, USA
}

Submitted 8 June 2012: Final revision received 24 October 2012: Accepted 11 November 2012: First published online 16 January 2013

\begin{abstract}
Objective: To examine whether the recent increasing prevalence of obesity was accompanied by variations in energy and macronutrient intakes by weight status. Design: Time series of cross-sectional surveys.

Setting: National Health and Nutrition Examination Surveys (NHANES) in the USA. Subjects: Adult participants of NHANES I (1971-1974), II (1976-1980), III (1988-1994) and continuous (1999-2004).

Results: Daily energy intake increased over time for men $(9832$ to $11652 \mathrm{~kJ}$, $P<0 \cdot 01)$ and women (6418 to $8142 \mathrm{~kJ}, P<0 \cdot 01)$ in all BMI classes. Percentage of energy intake from carbohydrate increased over time (men: $42 \cdot 7 \%$ to $48 \cdot 0 \%$, $P<0 \cdot 01$; women: $45 \cdot 4 \%$ to $50 \cdot 6 \%, P<0 \cdot 01$ ), whereas percentage of energy intake from fat (men: $36 \cdot 7 \%$ to $33 \cdot 1 \%, P<0 \cdot 01$; women: $36 \cdot 1 \%$ to $33 \cdot 8 \%$, $P<0 \cdot 01$ ) and protein (men: $16 \cdot 4 \%$ to $15 \cdot 1 \%, P<0 \cdot 01$; women: $16 \cdot 9 \%$ to $14 \cdot 7 \%$, $P<0 \cdot 01)$ decreased. With surveys combined, daily energy intake varied among BMI classes for women (underweight/normal weight: $7460 \mathrm{~kJ}$; overweight: $6799 \mathrm{~kJ}$; obese I: $7033 \mathrm{~kJ}$; obese II/III: $7401 \mathrm{~kJ} ; P<0 \cdot 01$ ) but not men. Percentage of energy intake from carbohydrate decreased with increasing BMI class (men: $46.6 \%$ to $45 \cdot 5 \%, P<0 \cdot 01$; women: $49 \cdot 0 \%$ to $48.6 \%, P<0 \cdot 01$ ) whereas percentage of energy intake from fat (men: $34 \cdot 3 \%$ to $36 \cdot 5 \%, P<0 \cdot 01$; women: $34 \cdot 4 \%$ to $35 \cdot 4 \%, P<0 \cdot 01$ ) and protein (men: $15 \cdot 3 \%$ to $16 \cdot 5 \%, P<0 \cdot 01$; women: $15 \cdot 2 \%$ to $16 \cdot 0 \%, P<0 \cdot 01)$ increased. Interactions of survey period and BMI class were not statistically significant.

Conclusions: Time trends in energy and macronutrient intakes were similar across BMI classes. Research examining how individuals respond differently to varying dietary compositions may provide greater insight about contributors to the rise in obesity.
\end{abstract}

In 2004, the Centers for Disease Control and Prevention (CDC) published an important article showing the trends in dietary intake in the USA from 1971 to 2000, the same period in which the prevalence of obesity more than doubled $^{(1)}$. The increased prevalence of obesity has been attributed both to increasing energy consumption and decreasing physical activity, among other potential aetiologies. Although a declining trend in physical activity has been more difficult to demonstrate ${ }^{(2-4)}$, the CDC authors found that energy intake increased in men by over $628 \mathrm{~kJ} / \mathrm{d}$ and in women by over $1255 \mathrm{~kJ} / \mathrm{d}$. Notably, the increase in energy came predominantly from carbohydrate sources, leading to the theory that this dietary trend may have fuelled the burgeoning obesity rate. Similar trends were seen in non-population-based data - the US Department of Agriculture's (USDA) food supply data showed an increase in daily per capita energy availability of $1757 \mathrm{~kJ}$ ( $420 \mathrm{kcal}$ ) in 1999 compared with 1971, and over $80 \%$ of this increase in energy came from carbohydrates ${ }^{(5)}$.

Support for this theory also comes from randomized trials examining the weight loss effects of varied levels of carbohydrate intake. Several trials have shown that a lowercarbohydrate diet typically leads to greater weight loss than a higher-carbohydrate diet, at least over relatively short periods (up to 6 months) ${ }^{(6)}$. When follow-up is extended beyond 6 months, however, results have been mixed, with some studies showing equivalent weight loss and others showing greater weight loss with the low-carbohydrate diet ${ }^{(6-8)}$. Given the dietary intake trends in the overall US population and recent trial data, examining how macronutrient composition relates to obesity could contribute information regarding the aetiology of the recent rise in obesity. 
The CDC study did not examine whether changes in consumption of energy, carbohydrate, protein and fat varied by BMI. To extend this prior study, we examined trends in intakes of energy and macronutrients of the National Health and Nutrition Examination Survey (NHANES) participants during 1971-2004 and whether the trends varied by BMI class. It is important to examine whether the overall trends in energy and macronutrient intakes masked differences among BMI classes. Such differences might elucidate associations between diet and obesity, providing insight into the potential factors contributing to the increasing prevalence of obesity. Our hypotheses were that energy consumption would increase with BMI (because of greater energy needs) and that carbohydrates would be an increasingly dominant source of extra energy intake. We also expected trends in energy and macronutrient consumption would diverge over time among BMI classes. If intake trends diverged over time among BMI classes, it might suggest that specific dietary patterns (e.g. high fat or high carbohydrate) might underlie the rising prevalence of obesity in the USA.

\section{Methods}

\section{Study design and data}

The NHANES are a series of nationally representative cross-sectional health examination surveys conducted by the National Center for Health Statistics of the CDC. Data were analysed from three of the earlier periodic NHANES (NHANES I conducted during 1971-1974, NHANES II during 1976-1980 and NHANES III during 1988-1994) and from three of the 2-year survey cycles of the continuous NHANES (1999-2000, 2001-2002 and 2003-2004). NHANES collects information on the health status of US civilian, non-institutionalized persons using a complex, multistage probability sample design. The study was conducted according to the guidelines laid down in the Declaration of Helsinki and all procedures involving human participants were approved by the National Center for Health Statistics Institutional Review Board. Written informed consent was obtained from all participants. Detailed descriptions of survey procedures and questionnaires have been published ${ }^{(9-15)}$.

\section{Study sample}

Overall response rates (i.e. percentage of the sample who completed interviews and examinations) for the surveys were as follows: 1971-1974 (74\%), 1976-1980 (73\%), 1988-1994 (78\%), 1999-2000 (76\%), 2001-2002 (80\%) and 2003-2004 $(76 \%)^{(16)}$. The present analyses were limited to individuals aged 20-74 years who completed the self-reported $24 \mathrm{~h}$ dietary recall (one per participant). The upper age limit was chosen for uniformity because 74 years was the upper age limit for NHANES I and NHANES II whereas subsequent surveys were not limited.
Participants were excluded if they reported consuming $0 \mathrm{~kJ}$ on the $24 \mathrm{~h}$ diet recall ( $n$ 4) or had missing BMI data ( $n$ 219). Further exclusions were made for participants with missing data on education ( $n$ 313), marital status ( $n$ 80), physical activity ( $n$ 415), atypical diet ( $n$ 186), employment status ( $n$ 76), and self-report of dieting ( $n$ 11). Analytic sample sizes ranged from 1714 men and 1985 women in NHANES 1999-2000 to 6630 men and 7537 women in NHANES III (Table 1).

\section{Interview and examination measurements}

NHANES consisted of a household interview followed by an interview and examination at a mobile examination centre $^{(9-15)}$. Weight and height were measured in all surveys using standardized procedures and equipment ${ }^{(9-15)}$. BMI, the explanatory variable of interest, was calculated by dividing weight in kilograms by the square of height in metres and classified according to guidelines ${ }^{(17)}$. Due to small sample sizes, the underweight (BMI $<18.5 \mathrm{~kg} / \mathrm{m}^{2}$ ) category was combined with normal weight $\left(\mathrm{BMI}=18 \cdot 5-24 \cdot 9 \mathrm{~kg} / \mathrm{m}^{2}\right)$ and class III obesity (BMI $\geq 40 \cdot 0 \mathrm{~kg} / \mathrm{m}^{2}$ ) was combined with class II obesity $\left(\mathrm{BMI}=35 \cdot 0-39 \cdot 9 \mathrm{~kg} / \mathrm{m}^{2}\right)$.

Race was defined as white, black and other. In the 1971-1974 and 1976-1980 surveys, race of the participant was 'marked by observation' by the interviewers who were instructed to record Mexican Americans, Puerto Ricans and persons of other Latin American descent as white, 'unless definitely known to be Black, American Indian, or other nonwhite race'. To remain consistent with this coding, participants who were 'Mexican American' or 'other Hispanic' were included in the white category for subsequent surveys. Physical activity was assessed differently during several of the surveys; therefore, participants were classified as 'more active', 'moderately active' or 'less active' as compared with their peers according to questions used in the 1988-1994 survey and after. For the earlier surveys, responses to two questions regarding leisure-time and non-leisure-time activity were collapsed into one physical activity variable using the 'more active', 'moderately active' or 'less active' responses. Other variables considered were age, marital status (married, not married), education (high school or less, or beyond high school) and employment status (working, for example at a job or business $v$. other categories, including keeping house). To assess for the possibility that the $24 \mathrm{~h}$ dietary recall was not representative of a person's typical intake, variables indicating weekday $v$. weekend day of the recall interview, self-report that the previous day's diet was atypical (yes or no) and self-report of current dieting for weight loss (yes or no) were included in the analyses.

\section{Dietary assessments}

The examination at the mobile examination centre included a $24 \mathrm{~h}$ dietary recall interview that assessed intake of all foods and beverages during the preceding day. Diet variables used as outcomes of interest in the 
Table 1 Characteristics of men and women aged 20-74 years - National Health and Nutrition Examination Surveys (NHANES), USA, $1971-2004^{*}$

\begin{tabular}{|c|c|c|c|c|c|c|c|c|c|c|c|c|}
\hline \multirow[b]{2}{*}{ Characteristic } & \multicolumn{2}{|c|}{$\begin{array}{l}\text { NHANES I } \\
1971-1974\end{array}$} & \multicolumn{2}{|c|}{$\begin{array}{l}\text { NHANES II } \\
1976-1980\end{array}$} & \multicolumn{2}{|c|}{$\begin{array}{l}\text { NHANES III } \\
\text { 1988-1994 }\end{array}$} & \multicolumn{2}{|c|}{$\begin{array}{l}\text { NHANES } \\
\text { 1999-2000 }\end{array}$} & \multicolumn{2}{|c|}{$\begin{array}{l}\text { NHANES } \\
2001-2002\end{array}$} & \multicolumn{2}{|c|}{$\begin{array}{l}\text { NHANES } \\
\text { 2003-2004 }\end{array}$} \\
\hline & Mean & SD & Mean & SD & Mean & SD & Mean & SD & Mean & SD & Mean & SD \\
\hline \multicolumn{13}{|l|}{ Men } \\
\hline$n$ & \multicolumn{2}{|c|}{4902} & \multicolumn{2}{|c|}{5568} & \multicolumn{2}{|c|}{6630} & \multicolumn{2}{|c|}{1714} & \multicolumn{2}{|c|}{1912} & \multicolumn{2}{|c|}{1804} \\
\hline Age (years) & $43 \cdot 02$ & 0.30 & $41 \cdot 98$ & 0.33 & $41 \cdot 83$ & $0 \cdot 39$ & $42 \cdot 81$ & $0 \cdot 41$ & $43 \cdot 30$ & 0.53 & $43 \cdot 34$ & 0.49 \\
\hline Race $(\%)$ & & & & & & & & & & & & \\
\hline White & $89 \cdot \varepsilon$ & & 87 & & 81 . & & 86 . & & 86 . & & $85 \cdot 90$ & \\
\hline Black & $9 \cdot($ & & & & 10 . & & 9. & 51 & 10 . & & $10 \cdot 19$ & \\
\hline Other & $1 \cdot 1$ & & & & 7 . & & 3. & 92 & 3. & 09 & 3.91 & \\
\hline BMI $\left(\mathrm{kg} / \mathrm{m}^{2}\right)$ & $25 \cdot 58$ & 0.08 & $25 \cdot 49$ & 0.07 & $26 \cdot 65$ & $0 \cdot 12$ & $27 \cdot 80$ & 0.23 & $28 \cdot 03$ & $0 \cdot 15$ & $28 \cdot 27$ & $0 \cdot 16$ \\
\hline BMI class $(\%)$ & & & & & & & & & & & & \\
\hline Underweight $\left(<18 \cdot 5 \mathrm{~kg} / \mathrm{m}^{2}\right) \dagger$ & $2 \cdot 4$ & & & & & & $1 \cdot$ & 28 & & 98 & $1 \cdot 19$ & \\
\hline Underweight/normal weight $\left(\leq 24.9 \mathrm{~kg} / \mathrm{m}^{2}\right)$ & $46 \cdot \varepsilon$ & & 48 & & 40 . & & 33. & & 29 . & & $28 \cdot 7 \varepsilon$ & \\
\hline Overweight $\left(25 \cdot 0-29 \cdot 9 \mathrm{~kg} / \mathrm{m}^{2}\right)$ & $41 \cdot 3$ & & 39 & & 40 . & & 39 . & & 42 . & & $39 \cdot 4$ & \\
\hline Obese class I $\left(30.0-34.9 \mathrm{~kg} / \mathrm{m}^{2}\right)$ & 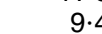 & & & & 14 . & & 17 . & & 18 . & & $22 \cdot 0$ & \\
\hline Obese class II/III $\left(\geq 35 \cdot 0 \mathrm{~kg} / \mathrm{m}^{2}\right)^{\prime}$ & $2 \cdot 3$ & & & & 5 . & & 9. & 89 & 9 . & 50 & $9 \cdot 7$ & \\
\hline Obese class III $\left(\geq 40.0 \mathrm{~kg} / \mathrm{m}^{2}\right) \dagger$ & 0.5 & & & & 1 . & & 3 & 27 & 3 . & 32 & $2 \cdot 98$ & \\
\hline Physical activity level (\%) & & & & & & & & & & & & \\
\hline More active & $42 \cdot$ & & 37 & & 37. & & 40 . & & 39 . & & $36 \cdot 8$ & \\
\hline Moderate active & $36 \cdot 2$ & & 38 & & 43. & & 43. & & 43 . & & 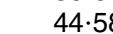 & \\
\hline Less active & $21 \cdot 5$ & & 24 & & 18 . & & 15 . & & 17. & & $18 \cdot 5$ & \\
\hline Married (\%) & $80 \cdot($ & & 74 & & 66 . & & 54. & & 62 . & & $60 \cdot 5$ & \\
\hline Education > high school (\%) & $34 \cdot 2$ & & 40 & & 44 . & & 51 . & & 56 . & & $55 \cdot 4$ & \\
\hline Employed (\%) & $79 \cdot 5$ & & 79 & & 79 . & & 75 . & & 75 . & & $71 \cdot 0$ & \\
\hline Atypical diet reported (\%) & & & & & & & & & & & & \\
\hline Eat more & $6 \cdot 5$ & & & & & & 12 . & & 10 . & & $7 \cdot 5$ & \\
\hline About the same & $75 \cdot 6$ & & 76 & & 88 . & & 60 . & & 60 . & & $72 \cdot 0$ & \\
\hline Eat less & $17 \cdot \varepsilon$ & & 15 & & 9 . & & 27 . & & 28 . & & $20 \cdot 4$ & \\
\hline Weekend day diet reported (\%) & $0 . \varsigma$ & & & & 24 . & & $32 \cdot$ & & 40 . & & $41 \cdot 6$ & \\
\hline Trying to lose or maintain weight (\%) & $3 \cdot 7$ & & & 39 & 31 . & & 42 . & & 42 . & & $45 \cdot 0$ & \\
\hline Women & & & & & & & & & & & & \\
\hline$n$ & 798 & & 62 & & 75 & & $19 \varepsilon$ & & 21 & & 1935 & \\
\hline Age (years) & $43 \cdot 02$ & $0 \cdot 30$ & $42 \cdot 61$ & $0 \cdot 33$ & $42 \cdot 50$ & $0 \cdot 40$ & $43 \cdot 77$ & 0.46 & $43 \cdot 46$ & 0.50 & 43.93 & 0.55 \\
\hline Race $(\%)$ & & & & & & & & & & & & \\
\hline White & 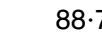 & & 86 & & 80 . & & 84. & & 84 . & & $83 \cdot 7 !$ & \\
\hline Black & 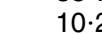 & & 10 & & 11 . & & 11. & & 11 . & & $12 \cdot 0$ & \\
\hline Other & $0 . \varsigma$ & & & & 7 . & & 3. & 20 & 4 . & 67 & 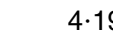 & \\
\hline BMI $\left(\mathrm{kg} / \mathrm{m}^{2}\right)$ & $25 \cdot 01$ & $0 \cdot 10$ & $25 \cdot 16$ & $0 \cdot 11$ & $26 \cdot 49$ & $0 \cdot 17$ & $28 \cdot 42$ & 0.28 & $28 \cdot 23$ & 0.22 & $28 \cdot 46$ & 0.25 \\
\hline BMI class $(\%)$ & & & & & & & & & & & & \\
\hline Underweight $\left(<18 \cdot 5 \mathrm{~kg} / \mathrm{m}^{2}\right) \dagger$ & $4 \cdot \varepsilon$ & & & & & & $2 \cdot$ & & $2 \cdot$ & & $2 \cdot 17$ & \\
\hline Underweight/normal weight $\left(\leq 24.9 \mathrm{~kg} / \mathrm{m}^{2}\right)$ & $59 \cdot 5$ & & 58 & & 49 . & & 37 . & & 38 . & & $37 \cdot 4$ & \\
\hline Overweight $\left(25 \cdot 0-29 \cdot 9 \mathrm{~kg} / \mathrm{m}^{2}\right)$ & $24 \cdot c$ & & 24 & & 25 . & & 28 . & & 27 . & & $27 \cdot 9$ & \\
\hline Obese class I $\left(30.0-34.9 \mathrm{~kg} / \mathrm{m}^{2}\right)$ & $10 \cdot \varepsilon$ & & 10 & & 14 . & & 17 . & & 18 . & & $18 \cdot 4$ & \\
\hline Obese class II/III $\left(\geq 35 \cdot 0 \mathrm{~kg} / \mathrm{m}^{2}\right)^{\prime}$ & $5 \cdot 5$ & & & & 10 . & & 17 . & & 15 . & & $16 \cdot 2($ & \\
\hline Obese class III $\left(\geq 40 \cdot 0 \mathrm{~kg} / \mathrm{m}^{2}\right) \dagger$ & $1 \cdot 7$ & & & & 4 . & & 6 & 54 & 6 . & 34 & $7 \cdot 2$ & \\
\hline Physical activity level (\%) & & & & & & & & & & & & \\
\hline More active & $29 \cdot 5$ & & 24 & & 28 . & & 31 . & & 31 . & & $32 \cdot 4$ & \\
\hline Moderate active & 38. & & 40 & & 45 . & & 46 . & & 42 . & & $42 \cdot 5$ & \\
\hline Less active & 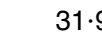 & & 34 & & 25 . & & 22 . & & 26 . & & $25 \cdot 0$ & \\
\hline Married (\%) & $71 \cdot$ & & 65 & & 60 . & & 49 . & & 59 . & & $56 \cdot 7$ & \\
\hline Education > high school (\%) & 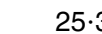 & & 31. & & 40 . & & 50 . & & 57 . & & $58 \cdot 3$ & \\
\hline Employed (\%) & $41 \cdot$ & & 47 & & 62 . & & 58. & & 58. & & $59 \cdot 3$ & \\
\hline Atypical diet reported (\%) & & & & & & & & & & & & \\
\hline Eat more & $8 \cdot 3$ & & 10 & & 2 . & & 14 . & & 8 . & & $8 \cdot 9$ & \\
\hline About the same & $68 \cdot($ & & 66 & & 88 . & & 56 . & & 63. & & $68 \cdot 7$ & \\
\hline Eat less & $23 \cdot 6$ & & 22 & & 8 . & & 29 . & & 27 . & & $22 \cdot 3$ & \\
\hline Weekend day diet reported (\%) & 0.6 & & & & 21 . & & 31 . & & 39 . & & $39 \cdot 6$ & \\
\hline Trying to lose or maintain weight (\%) & $8 \cdot \varepsilon$ & & 11 & & 52 . & & 60. & & 56 . & & $59 \cdot 0$ & \\
\hline
\end{tabular}

Data are presented as mean and standard deviation except where noted otherwise.

${ }^{*}$ Because of differences in the age distribution across surveys, estimates of population characteristics were adjusted by direct standardization to the 2000 US Census population using the age groups 20-39 years, 40-59 years and 60-74 years.

tIn the regression analyses, underweight was combined with normal weight and obese class III was combined with obese class II due to the small prevalence of underweight and obese class III in the sample. 
current analysis included total energy intake in kilojoules, and total fat, protein and carbohydrate intakes as percentages of total energy intake. Percentage of total energy intake from alcohol was not included in the analyses. Although there have been changes in the dietary interview methodology and food composition databases used in the surveys, there was sufficient comparability to allow comparison of overall energy and macronutrient intakes. Dietary interviews did not include weekend days in 1971-1974 and 1976-1980, while the subsequent surveys did include weekend days. This difference was addressed in the analytic approach.

\section{Estimation}

Because of differences in the age distribution across surveys, estimates of population characteristics were adjusted by direct standardization to the 2000 US Census population using the age groups 20-39 years, 40-59 years and 60-74 years (Table 1). Generalized linear models with a normal distribution and identity link function were applied to the proportion of total energy intake from carbohydrate and fat because the nutrient intakes were normally distributed. Given the non-normal distribution of total energy intake and the proportion of total energy intake from protein, generalized linear models with a normal distribution and log link function were applied. Regression analyses were stratified by sex. Regression models were used to predict nutrient intakes adjusted for the characteristics described above representing important secular, health and health habit changes over the study period.

These regression models were used to generate adjusted total energy consumption and adjusted proportions of total energy from carbohydrate, protein and fat to assess differences among BMI classes and across time. Statistical significance of explanatory variables was determined using Sattherwaite-adjusted $F$ tests with an $\alpha$ level of 0.05 , including tests of trend over time using the survey variable and tests of BMI class differences using the BMI class variable. The interaction between survey and BMI class was used to examine whether BMI class differences in energy and macronutrient intakes may have changed over time. The interaction term was not statistically significant in any of the models, so $P$ values for the main effects of time (i.e. survey) and BMI class are presented. All analyses were performed using the statistical software package SAS-callable SUDAAN release 9·0·1 (2005), to apply survey sampling weights and survey design variables for estimating standard errors that account for the complex sample design, survey non-response and oversampling to obtain nationally representative results.

\section{Results}

\section{Participant characteristics}

The proportion of NHANES respondents of white race decreased over time from $89.9 \%$ to $85.9 \%$ in men $(P<0 \cdot 01)$ and from $88.8 \%$ to $83.8 \%$ in women $(P<0.01$; Table 1). Obesity, high-school education and attempts at weight management became more prevalent over time in men and women (all $P<0 \cdot 01$ ). Cigarette smoking and married status became less prevalent in men and women (all $P<0 \cdot 01)$. Employment decreased in men $(P<0 \cdot 01)$ and increased in women $(P<0 \cdot 01)$.

\section{Trends in intakes of energy and macronutrients over time}

To understand whether energy and macronutrient intakes changed from 1971 to 2004 irrespective of BMI class, we examined time trends for the pooled sample (Table 2). From 1971 to 2004 , there was a significant increase in total energy intake for men (9832 to $11652 \mathrm{~kJ} / \mathrm{d}, P<0 \cdot 01$ for trend) and women ( 6418 to $8142 \mathrm{~kJ} / \mathrm{d}, P<0 \cdot 01$ for trend), adjusting for BMI class and other variables. The amount and proportion of total energy intake from carbohydrate also increased over time in men $(42.7 \%$ to $48.0 \%$, $P<0 \cdot 01$ for trend) and women ( $45 \cdot 4 \%$ to $50 \cdot 6 \% P<0 \cdot 01$ for trend). From 1971 to 2004, there was an increase in amount but a significant decrease in the proportion of total energy intake from fat for men $(36 \cdot 7 \%$ to $33 \cdot 1 \%$, $P<0 \cdot 01$ for trend) and women $(36 \cdot 1 \%$ to $33 \cdot 8 \% P<0 \cdot 01$

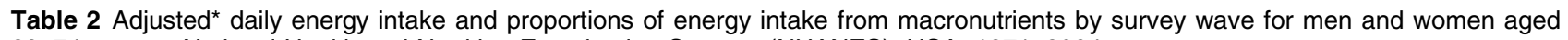
20-74 years - National Health and Nutrition Examination Surveys (NHANES), USA, 1971-2004

\begin{tabular}{|c|c|c|c|c|c|c|c|c|}
\hline \multirow[b]{2}{*}{ Survey years } & \multicolumn{2}{|c|}{$\begin{array}{l}\text { Adjusted total } \\
\text { energy (kJ) }\end{array}$} & \multicolumn{2}{|c|}{$\begin{array}{l}\text { Adjusted proportion of energy } \\
\text { from carbohydrate (\%) }\end{array}$} & \multicolumn{2}{|c|}{$\begin{array}{l}\text { Adjusted proportion of } \\
\text { energy from fat }(\%)\end{array}$} & \multicolumn{2}{|c|}{$\begin{array}{l}\text { Adjusted proportion of } \\
\text { energy from protein (\%) }\end{array}$} \\
\hline & Ment & Woment & Ment & Woment & Ment & Woment & Ment & Woment \\
\hline $1971-1974$ & 9832 & 6418 & $42 \cdot 7$ & $45 \cdot 4$ & $36 \cdot 7$ & $36 \cdot 1$ & $16 \cdot 4$ & $16 \cdot 9$ \\
\hline $1976-1980$ & 9824 & 6309 & $42 \cdot 8$ & $46 \cdot 1$ & $36 \cdot 7$ & $36 \cdot 0$ & $16 \cdot 1$ & $16 \cdot 0$ \\
\hline 1988-1994 & 10669 & 7410 & $48 \cdot 1$ & $50 \cdot 9$ & $34 \cdot 0$ & $33 \cdot 4$ & $15 \cdot 4$ & $15 \cdot 2$ \\
\hline 1999-2000 & 11230 & 8121 & $49 \cdot 5$ & $52 \cdot 5$ & $32 \cdot 3$ & $32 \cdot 4$ & $15 \cdot 2$ & $14 \cdot 6$ \\
\hline 2001-2002 & 11527 & 8155 & $49 \cdot 4$ & $52 \cdot 2$ & $32 \cdot 7$ & $33 \cdot 3$ & $14 \cdot 9$ & $14 \cdot 5$ \\
\hline 2003-2004 & 11652 & 8142 & $48 \cdot 0$ & $50 \cdot 6$ & $33 \cdot 1$ & $33 \cdot 8$ & $15 \cdot 1$ & $14 \cdot 7$ \\
\hline
\end{tabular}

*Adjusted for BMI, age, race, physical activity, marital status, education, employment status, day of the week of the dietary recall, self-reported atypical and self-report of current dieting for weight loss.

$+P<0.01$ for trend over time (i.e. over surveys) using the Sattherwaite-adjusted $F$ test adjusting for BMI class and other explanatory variables. 
Table 3 Adjusted* daily energy intake and proportions of energy intake from macronutrients by survey wave and BMI category for men and women aged 20-74 years - National Health and Nutrition Examination Surveys (NHANES), USA, 1971-2004

\begin{tabular}{|c|c|c|c|c|c|c|c|c|}
\hline \multirow[b]{2}{*}{ Survey years } & \multicolumn{4}{|c|}{ Men } & \multicolumn{4}{|c|}{ Women } \\
\hline & $\begin{array}{l}\text { Underweight/ } \\
\text { normal weight }\end{array}$ & Overweight & $\begin{array}{l}\text { Obese } \\
\text { class I }\end{array}$ & $\begin{array}{l}\text { Obese } \\
\text { class II/III }\end{array}$ & $\begin{array}{l}\text { Underweight/ } \\
\text { normal weight }\end{array}$ & Overweight & Obese class I & $\begin{array}{l}\text { Obese } \\
\text { class II/III }\end{array}$ \\
\hline \multicolumn{9}{|c|}{ Adjusted energy intake (kJ) } \\
\hline $1971-1974$ & 10196 & 9435 & 9255 & 9393 & 6694 & 6042 & 6109 & 6289 \\
\hline 1976-1980 & 10217 & 9406 & 9263 & 9339 & 6598 & 5933 & 6017 & 6163 \\
\hline 1988-1994 & 11109 & 10393 & 10251 & 10422 & 7753 & 7079 & 7196 & 7452 \\
\hline 1999-2000 & 11903 & 10791 & 10565 & 10657 & 8573 & 7669 & 7761 & 8017 \\
\hline 2001-2002 & 12230 & 11021 & 10878 & 10933 & 8611 & 7686 & 7824 & 8042 \\
\hline 2003-2004 & 12414 & 11083 & 11008 & 11171 & 8619 & 7640 & 7816 & 8100 \\
\hline All surveys & 10979 & 10159 & 10125 & 10372 & $7460 t$ & $6799+$ & $7033+$ & $7401+$ \\
\hline \multicolumn{9}{|c|}{ Adjusted proportion of energy from carbohydrate (\%) } \\
\hline $1971-1974$ & $43 \cdot 3$ & $42 \cdot 2$ & $41 \cdot 2$ & $41 \cdot 0$ & $45 \cdot 5$ & $45 \cdot 5$ & $45 \cdot 1$ & $44 \cdot 4$ \\
\hline 1976-1980 & $43 \cdot 5$ & $42 \cdot 4$ & $41 \cdot 3$ & $41 \cdot 1$ & $46 \cdot 2$ & $46 \cdot 2$ & $45 \cdot 7$ & $45 \cdot 1$ \\
\hline $1988-1994$ & $49 \cdot 0$ & $48 \cdot 0$ & $46 \cdot 9$ & $46 \cdot 7$ & $51 \cdot 3$ & $51 \cdot 1$ & $50 \cdot 4$ & $49 \cdot 6$ \\
\hline 1999-2000 & $50 \cdot 6$ & $49 \cdot 2$ & $48 \cdot 1$ & $47 \cdot 8$ & $53 \cdot 2$ & $52 \cdot 5$ & $51 \cdot 9$ & $50 \cdot 9$ \\
\hline 2001-2002 & $50 \cdot 4$ & $49 \cdot 1$ & $48 \cdot 0$ & $47 \cdot 7$ & $52 \cdot 9$ & $52 \cdot 2$ & $51 \cdot 5$ & $50 \cdot 7$ \\
\hline 2003-2004 & $49 \cdot 1$ & $47 \cdot 7$ & $46 \cdot 6$ & $46 \cdot 3$ & $51 \cdot 3$ & $50 \cdot 6$ & $49 \cdot 9$ & $49 \cdot 0$ \\
\hline All surveys & $46 \cdot 6+$ & $45 \cdot 8+$ & $45 \cdot 2 \dagger$ & $45 \cdot 5 t$ & $49 \cdot 0+$ & $49 \cdot 1+$ & $49 \cdot 0+$ & $48 \cdot 6+$ \\
\hline \multicolumn{9}{|c|}{ Adjusted proportion of energy from fat (\%) } \\
\hline $1971-1974$ & $36 \cdot 2$ & $36 \cdot 7$ & $38 \cdot 0$ & $39 \cdot 0$ & $35 \cdot 9$ & $35 \cdot 9$ & $36 \cdot 6$ & $37 \cdot 4$ \\
\hline $1976-1980$ & $36 \cdot 2$ & $36 \cdot 7$ & $38 \cdot 1$ & $39 \cdot 1$ & $35 \cdot 8$ & $35 \cdot 9$ & $36 \cdot 6$ & $37 \cdot 3$ \\
\hline $1988-1994$ & $33 \cdot 3$ & $33 \cdot 8$ & $35 \cdot 2$ & $36 \cdot 3$ & $33 \cdot 2$ & $33 \cdot 2$ & $33 \cdot 9$ & $34 \cdot 8$ \\
\hline 1999-2000 & $31 \cdot 4$ & $32 \cdot 2$ & $33 \cdot 6$ & $34 \cdot 6$ & $32 \cdot 0$ & $32 \cdot 2$ & $32 \cdot 9$ & 33.9 \\
\hline $2001-2002$ & $31 \cdot 8$ & $32 \cdot 6$ & $34 \cdot 1$ & $35 \cdot 2$ & $32 \cdot 9$ & $33 \cdot 1$ & 33.9 & $34 \cdot 9$ \\
\hline 2003-2004 & $32 \cdot 1$ & $33 \cdot 0$ & $34 \cdot 4$ & $35 \cdot 5$ & $33 \cdot 3$ & $33 \cdot 5$ & $34 \cdot 4$ & $35 \cdot 3$ \\
\hline All surveys & $34 \cdot 3+$ & $34 \cdot 7 \dagger$ & $35 \cdot 7 \dagger$ & $36 \cdot 5 t$ & $34 \cdot 4+$ & $34 \cdot 2 \dagger$ & $34 \cdot 7 \dagger$ & $35 \cdot 4+$ \\
\hline \multicolumn{9}{|c|}{ Adjusted proportion of energy from protein (\%) } \\
\hline $1971-1974$ & $16 \cdot 1$ & $16 \cdot 7$ & $17 \cdot 0$ & $17 \cdot 3$ & $16 \cdot 6$ & $17 \cdot 2$ & $17 \cdot 3$ & $17 \cdot 5$ \\
\hline $1976-1980$ & $15 \cdot 7$ & $16 \cdot 3$ & $16 \cdot 7$ & $17 \cdot 0$ & $15 \cdot 7$ & $16 \cdot 4$ & $16 \cdot 4$ & $16 \cdot 7$ \\
\hline 1988-1994 & $14 \cdot 9$ & $15 \cdot 6$ & $16 \cdot 0$ & $16 \cdot 4$ & $14 \cdot 7$ & $15 \cdot 5$ & $15 \cdot 7$ & $15 \cdot 9$ \\
\hline 1999-2000 & $14 \cdot 5$ & $15 \cdot 4$ & $15 \cdot 8$ & $16 \cdot 3$ & $14 \cdot 0$ & $14 \cdot 9$ & $15 \cdot 1$ & $15 \cdot 4$ \\
\hline 2001-2002 & $14 \cdot 2$ & $15 \cdot 1$ & $15 \cdot 6$ & $15 \cdot 9$ & $13 \cdot 8$ & $14 \cdot 9$ & $15 \cdot 0$ & $15 \cdot 3$ \\
\hline 2003-2004 & $14 \cdot 4$ & $15 \cdot 3$ & $15 \cdot 8$ & $16 \cdot 1$ & $14 \cdot 1$ & $15 \cdot 1$ & $15 \cdot 3$ & $15 \cdot 5$ \\
\hline All surveys & $15 \cdot 3+$ & $15 \cdot 9+$ & $16 \cdot 2+$ & $16 \cdot 5 t$ & $15 \cdot 2+$ & $15 \cdot 9+$ & $15 \cdot 9+$ & $16 \cdot 0 t$ \\
\hline
\end{tabular}

*Adjusted for age, race, physical activity, marital status, education, employment status, day of the week of the dietary recall, self-reported atypical diet and self-report of current dieting for weight loss.

$+P<0.01$ for trend over BMI classes using the Sattherwaite-adjusted $F$ test adjusting for survey wave and other explanatory variables.

for trend). The proportion of total energy intake from protein also decreased over time (men: $16 \cdot 4 \%$ to $15 \cdot 1 \%, P<0 \cdot 01$ for trend; women: $16.9 \%$ to $14 \cdot 7 \% P<0 \cdot 01$ for trend), even though the total amount of energy intake increased.

\section{Trends in intakes of energy and macronutrients by BMI classification}

To understand whether energy and macronutrient intakes changed from 1971 to 2004 differentially across BMI classes and whether these differences were masked in pooled results from Table 2, we examined time trends stratified by BMI class. In men, average total energy intake between 1971 and 2004 was similar among the BMI categories (range: $10125 \mathrm{~kJ} / \mathrm{d}$ in obese class I to $10979 \mathrm{~kJ} / \mathrm{d}$ in underweight/normal weight, $P=$ NS for trend), adjusting for survey period and other variables (Table 3 and Fig. 1). In women, total energy intake was highest for underweight/normal weight $(7460 \mathrm{~kJ} / \mathrm{d})$, lowest in overweight women $(6799 \mathrm{~kJ} / \mathrm{d})$ and then rose gradually in the obese categories $(P<0 \cdot 01$ for trend).
However, the quadratic trend was not statistically significant (Table 3 and Fig. 1).

In men, the proportion of total energy intake from carbohydrate declined with increasing BMI category ( $46.6 \%$ in underweight/normal weight to $45.5 \%$ in obese class II/III, $P<0.01$ for trend), after adjusting for survey period and other variables (Table 3 and Fig. 2(a)). In women, the decline across BMI classes was slighter $(0 \cdot 4$ percentage points $)$ but still statistically significant $(P<0 \cdot 01$ for trend). The largest difference between any two BMI classes in a single survey was $2 \cdot 8$ percentage points in men (underweight/normal weight: $49 \cdot 1 \%$, obese class II/III: $46 \cdot 3 \%$, in 2003-2004) and $2 \cdot 3$ percentage points in women, occurring in both the 1999-2000 and 2003-2004 surveys (Table 3 and Fig. 2(b)).

The proportion of dietary fat increased as BMI class increased in men $(34.3 \%$ in underweight/normal weight to $36.5 \%$ in obese class II/III, $P<0 \cdot 01$ for trend), adjusting for survey period and other variables. In women, the pattern was the same but the increase in 


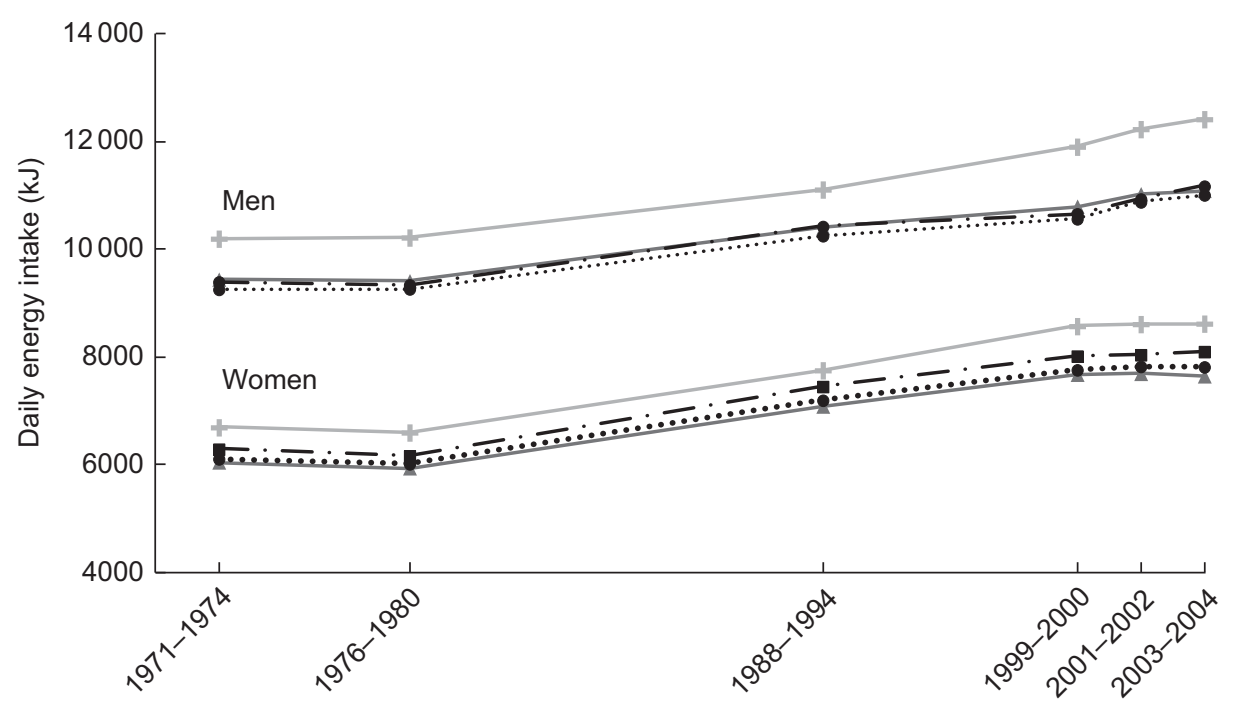

Fig. 1 Adjusted daily energy intake by BMI (-+, underweight/normal weight; $-\leftarrow$, overweight; ..๑・. obese class I; (NHANES), USA, 1971-2004 $(1 \mathrm{kcal}=4 \cdot 184 \mathrm{~kJ})$

proportion of dietary fat as BMI class increased was smaller $(34 \cdot 4 \%$ in underweight/normal weight to $35 \cdot 4 \%$ in obese class II/III, $P<0 \cdot 01$ for trend). The proportion of energy from protein increased slightly but significantly as BMI class increased from underweight/normal weight to obese class II/III (from $15 \cdot 3 \%$ to $16 \cdot 5 \%$ in men; from $15 \cdot 2 \%$ to $16 \cdot 0 \%$ in women; all $P<0 \cdot 01$ ), adjusting for survey and other variables.

\section{Discussion}

From 1971 to 2004 in the USA, daily energy intake and the percentage of daily energy from carbohydrate increased substantially, whereas the percentages of daily energy from fat and protein declined. These results are consistent with a prior study that did not adjust for the full set of demographic, health status, physical activity and dietary behaviour variables considered here ${ }^{(18)}$. The types of foods that explain these changes in macronutrient composition in the American diet were not a focus of the present study, but previous research has demonstrated that intakes of sugared beverages and fast foods increased substantially over the time period of the surveys ${ }^{(19)}$. The decline in percentage of daily energy from fat may indicate that the US population altered dietary intake in response to the USDA's messages to reduce dietary fat. Unfortunately, the decrease in percentage fat intake was more than compensated with an increased intake of carbohydrate that was predominantly refined starches and sugars ${ }^{(19)}$.

We expected that these overall trends of increasing energy and carbohydrate intakes would mask meaningful differences in trends among BMI classes. Contrary to our expectations, differences among BMI classes in the intake of energy and macronutrient composition were modest. Obese individuals reported consuming less energy each day, and a somewhat smaller percentage of energy from carbohydrate, compared with underweight/normal weight individuals. These results suggest that obese individuals did not, as one would expect from our current understanding of maintenance energy requirements, consume more energy than their underweight/normal weight peers, nor did they consume diets that were dramatically different in macronutrient content. This indicates that increasing trends in energy consumption are of concern for all BMI classes, not just for individuals in the highest BMI classes.

Several cross-sectional studies have found negative or no associations between energy intake and $\mathrm{BMI}^{(20-25)}$; the current study extends this finding over multiple time points in the US population. According to current understanding of energy balance, however, obese individuals should consume considerably more energy per day than normal weight individuals to maintain their weight. For example, using an equation commonly used for calculating energy requirements, a 45-year-old sedentary man of average height $(1.78 \mathrm{~m})$ who weighed $70 \mathrm{~kg}$ $\left(\mathrm{BMI}=220 \mathrm{~kg} / \mathrm{m}^{2}\right)$ would require $9606 \mathrm{~kJ} / \mathrm{d}$ to maintain that weight; a man of the same age, height and activity level who weighed $120 \mathrm{~kg}\left(\mathrm{BMI}=380 \mathrm{~kg} / \mathrm{m}^{2}\right)$ would require $12962 \mathrm{~kJ} / \mathrm{d}$, a difference of $\sim 3347 \mathrm{~kJ} / \mathrm{d}^{(26)}$. This contrasts with the finding in the current study that adjusted energy intakes in the lowest and highest BMI classes differed by only $209-1255 \mathrm{~kJ} / \mathrm{d}$ in each of the surveys. 

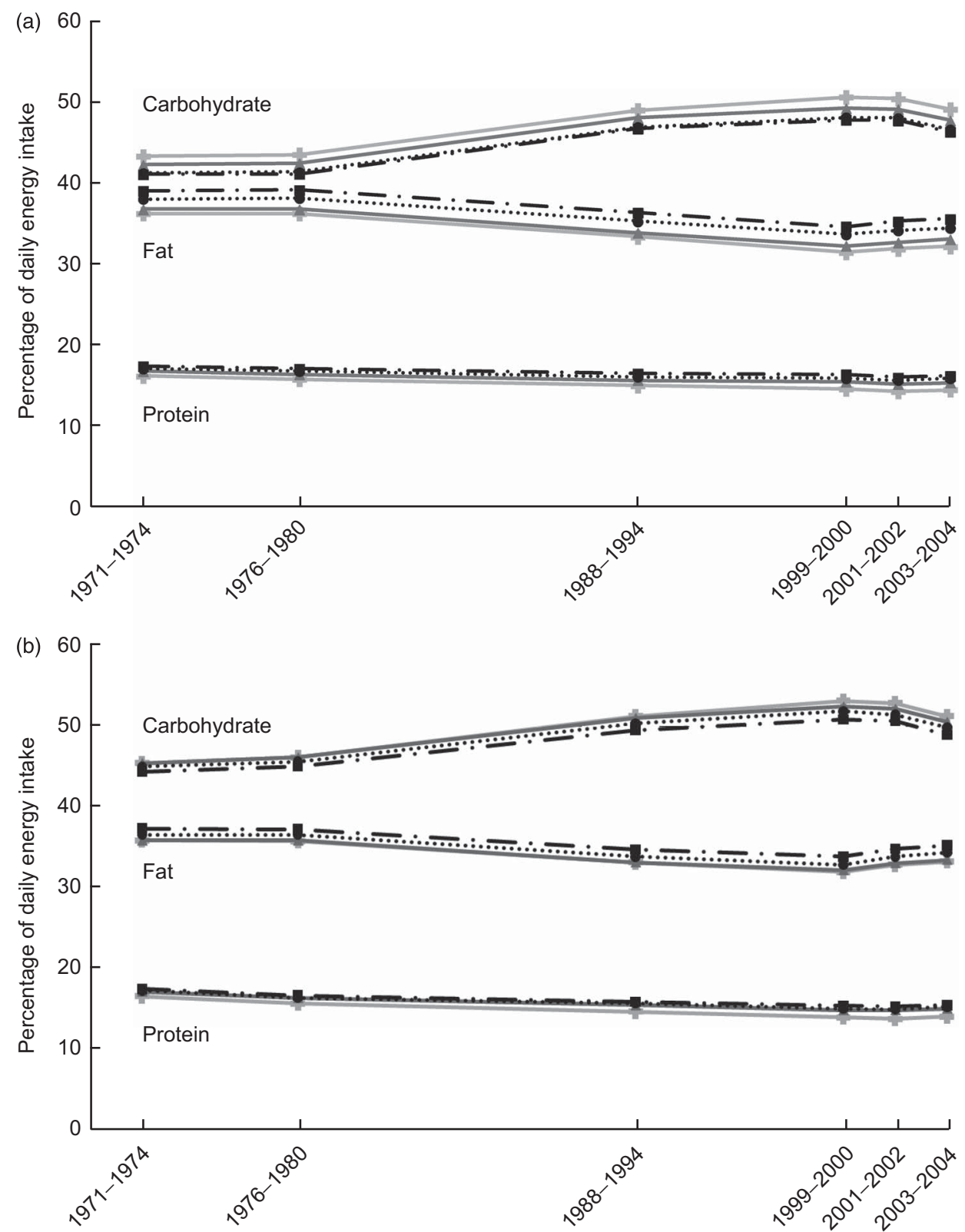

Fig. 2 Adjusted percentage of daily energy intake from macronutrients by survey wave and BMI (-+-, underweight/normal weight; -, overweight; ....., obese class I; _- - obese class II/III) for men (a) and women (b) aged 20-74 years - National Health and Nutrition Examination Surveys (NHANES), USA, 1971-2004

Several reasons have been given for the compressed range of daily energy intake among the BMI classes. Two common postulates are that obese individuals are less active or are more likely to be restricting food intake. For example, Ballard-Barbash et al. examined $24 \mathrm{~h}$ dietary recall data from the USDA's 1985-1986 Continuing Surveys of Food Intakes by Individuals (CSFII) and found that overweight women were twice as likely than normal weight women to report energy restriction/weight loss dieting $(15 \% v .7 \%)$ but less likely to report moderate or heavy leisure activity $(50 \% v \cdot 64 \%)^{(20)}$. Physical activity level, atypical dietary intake and whether the individual was 'dieting' were considered in the present analyses but residual confounding may be present.

Another common explanation is that obese people under-report food intake more than their thinner counterparts. This belief is based on studies comparing self-reported dietary intake with more objective methods such as estimated energy requirements from calculated BMR (using an equation that includes age, sex, height and weight), subsequent measured intake of supplied food, or extrapolated measures of energy intake (i.e. doubly labelled water ${ }^{(20,22,25,27)}$. The doubly labelled water method, which actually measures energy expenditure 
rather than intake, is currently considered the gold standard. One compelling finding from these studies is that while most participants underestimate energy intake, the magnitude of underestimation increases as BMI increases ${ }^{(20,27-30)}$. Unfortunately, all of these objective methods for estimating energy intake have limitations such that determining whether and how much someone is under-reporting remains difficult.

Previous studies have found that obese individuals consume a smaller proportion of daily energy from carbohydrate than their thinner counterparts and/or a larger proportion of energy from protein ${ }^{(31-33)}$. In an analysis of the USDA's 1994-1996 CSFII, Bowman and Spence divided participants into four groups based on their percentage of energy intake from carbohydrate (0-30\%, $30-45 \%, 45-55 \%$, above $55 \%$ ) and found that women in the highest carbohydrate intake group had the lowest mean BMI $\left(25 \cdot 2 v \cdot 25 \cdot 7-26 \cdot 7 \mathrm{~kg} / \mathrm{m}^{2}\right)^{(33)}$. The relationship was not obvious in men, however, with the mean BMI being similar in the lowest and highest carbohydrate intake groups. Whether certain patterns of macronutrient intake actually lead to weight gain or whether people of high BMI tend to consume a certain macronutrient pattern is more difficult to discern. Clinical trials have demonstrated that weight loss can result from diets that are either high or low in carbohydrate composition ${ }^{(6,34,35)}$. Examining this issue in prospective studies that repeatedly collect both dietary intake and body weight data may provide further insight.

Our results also highlight several other demographic and lifestyle trends in the USA over the covered time period. The percentage of whites in the sample trended downward across surveys, reflecting trends in the general population in which the percentage of whites declined from $88.6 \%$ in 1960 to $75 \cdot 1 \%$ in 2000 , while the percentage of blacks and races other than white or black increased from $10 \cdot 5 \%$ to $12 \cdot 3 \%$ and from $<5 \%$ to $12 \cdot 5 \%$, respectively $^{(36)}$. Starting with NHANES III (1988-1994), the prevalence of obesity increased while the prevalence of normal weight declined and the prevalence of overweight remained stable, as has been described ${ }^{(37,38)}$. In a similar pattern, there were substantive increases in the percentage of participants reporting they were trying to lose or maintain weight, likely reflecting the increasing prevalence of obesity that was occurring. The $24 \mathrm{~h}$ diet recall was also described as atypical more frequently in the later surveys, which likely signals changes in eating habits in that era (e.g. increased eating at restaurants). Physical activity did not change as dramatically but there was a mild decrease across surveys in the percentage of participants who reported being less active or more active, whereas the percentage who reported being moderately active increased.

There are some limitations to the present study to consider. As with other population research, dietary intake information was self-reported by participants and thus subject to recall bias. To reduce bias and enhance data quality, the survey uses standardized mobile examination centres, highly trained staff and validated questionnaires. Another limitation is that the interview methods for collecting information changed somewhat over the surveys ${ }^{(39)}$. For example, dietary intake on weekend days was not included in NHANES I and II but was included in subsequent surveys. The physical activity assessment also changed over the surveys and was brief, allowing potential residual confounding. Also, because information on cigarette smoking was missing for a large proportion of participants in the 1971-1974 survey, smoking was not included in the regression models. Smokers tend to have lower BMI but higher intakes of energy and fat than non-smokers; therefore, adjusting for smoking status might result in more dramatic increases in energy and fat intakes with increasing BMI. Estimates were quite similar, however, when these variables were included in the models. To minimize the impact of these method changes, only those variables that were measured consistently over the surveys were used and variables for atypical diet and day of the week being reported were included. Because analyses of NHANES data must rely upon a cross-sectional time-series study design, it is not possible to examine diet and weight changes longitudinally in the same individuals. These results are strengthened, however, by their generalizability to the US population because the surveys used national probability samples.

\section{Conclusions}

Over the past 35 years in the USA when obesity has become increasingly prevalent, the intakes of energy and macronutrients among people of different BMI classes trended similarly over time. From these results, population trends in fat or carbohydrate intake do not clearly explain the rise in obesity prevalence. Research examining how individuals respond differently to varying macronutrient compositions may provide greater insight about dietary contributors to the rise in obesity.

\section{Acknowledgements}

Sources of funding: This material is the result of work supported with resources and the use of facilities at the Durham VA Medical Center. W.S.Y. was supported by a Health Services Research Career Development Award (RCD 02-183-1) from the Department of Veterans Affairs during work on this project. The views expressed in this article are those of the authors and do not necessarily reflect the position or policy of the Department of Veterans Affairs, Duke University, or the Research Triangle Institute. Conflicts of interest: W.S.Y. and C.-C.W. have no competing interests to declare. M.L.M. has received consulting fees from Takeda 
Pharmaceuticals, Novartis and the Surgical Review Corporation. Authors' contributions: W.S.Y. contributed to the study conception and design, interpretation of data, and drafting the article and revising it critically for important intellectual content. C.-C.W. contributed to the acquisition of data, analysis of data, and revising the article critically for important intellectual content. M.L.M. contributed to the study conception and design, interpretation of data, and revising the article critically for important intellectual content. All authors provided final approval of the version to be published. W.S.Y. had full access to all of the data in the study and takes responsibility for the integrity of the data and the accuracy of the data analysis.

\section{References}

1. Centers for Disease Control and Prevention (2004) Trends in intake of energy and macronutrients - United States, 1971-2000. MMWR Morb Mortal Wkly Rep 53, 80-82.

2. Centers for Disease Control and Prevention (2001) Physical activity trends - United States, 1990-1998. MMWR Morb Mortal Wkly Rep 50, 166-169.

3. Centers for Disease Control and Prevention (2004) Prevalence of no leisure-time physical activity - 35 States and the District of Columbia, 1988-2002. MMWR Morb Mortal Wkly Rep 53, 82-86.

4. Carlson SA, Fulton JE, Schoenborn CA et al. (2010) Trend and prevalence estimates based on the 2008 Physical Activity Guidelines for Americans. Am J Prev Med 39, 305-313.

5. US Department of Agriculture, Economic Research Service (2012) Food Availability (Per Capita) Data System. http://www.ers.usda.gov/data-products/food-availability(per-capita)-data-system.aspx\#26705 (accessed December 2012).

6. Nordmann AJ, Nordmann A, Briel M et al. (2006) Effects of low-carbohydrate vs low-fat diets on weight loss and cardiovascular risk factors: a meta-analysis of randomized controlled trials. Arch Intern Med 166, 285-293.

7. Foster GD, Wyatt HR, Hill JO et al. (2010) Weight and metabolic outcomes after 2 years on a low-carbohydrate versus low-fat diet: a randomized trial. Ann Intern Med 153, 147-157.

8. Shai I, Schwarzfuchs D, Henkin Y et al. (2008) Weight loss with a low-carbohydrate, Mediterranean, or low-fat diet. $N$ Engl J Med 359, 229-241.

9. Centers for Disease Control and Prevention, National Health and Nutrition Examination Survey (1999) NHANES 1999-2000 Survey Operations Manuals, Consent Documents, Brochures. Hyattsville, MD: CDC; available at http://www.cdc.gov/nchs/nhanes/nhanes1999-2000/current_ nhanes_99_00.htm

10. Centers for Disease Control and Prevention, National Center for Health Statistics (2002) NHANES 2001-02 Procedures Manuals. Hyattsville, MD: CDC; available at http://www.cdc. gov/nchs/about/major/nhanes/current_nhanes_01_02.htm

11. Centers for Disease Control and Prevention, National Health and Nutrition Examination Survey (1996) NHANES III Reports and Reference Manuals. Hyattsville, MD: CDC; available at http://www.cdc.gov/nchs/nhanes/nh3rrm. htm\#manuals

12. National Center for Health Statistics (2005) NHANES 2003-2004 Survey Operations Manuals, Brochures, Consent Documents. Hyattsville, MD: CDC; available at http://www.cdc.gov/nchs/nhanes/nhanes2003-2004/current_ nhanes_03_04.htm

13. US Department of Health and Human Services, National Center for Health Statistics (1981) Plan and Operation of the second National Health and Nutrition Examination Survey, United States: 1976-1980. Hyattsville, MD: NCHS; available at http://www.cdc.gov/nchs/data/series/sr_01/ sr01_015.pdf.

14. US Department of Health Education and Welfare (1973) Plan and Operation of the Health and Nutrition Examination Survey, United States - 1971-1973: Part A. Development, Plan and Operation. Hyattsville, MD: NCHS.

15. US Department of Health Education and Welfare (1977) Plan and Operation of the Health and Nutrition Examination Survey, United States - 1971-1973: Part B. Data Collection Forms of the Survey. Hyattsville, MD: NCHS.

16. Centers for Disease Control and Prevention (various years) NHANES Response Rates and CPS Totals. http://www. cdc.gov/nchs/nhanes/response_rates_CPS.htm (accessed March 2012).

17. NHLBI Obesity Education Initiative Expert Panel on the Identification, Evaluation, and Treatment of Overweight and Obesity in Adults (1998) Clinical Guidelines on the Identification, Evaluation, and Treatment of Overweight and Obesity in Adults: the Evidence Report. NIH Publication no. 98-4083. Bethesda, MD: US Department of Health and Human Services, Public Health Service, National Institutes of Health, National Heart, Lung, and Blood Institute.

18. Austin GL, Ogden LG \& Hill JO (2011) Trends in carbohydrate, fat, and protein intakes and association with energy intake in normal-weight, overweight, and obese individuals: 1971-2006. Am J Clin Nutr 93, 836-843.

19. Nielsen SJ \& Popkin BM (2003) Patterns and trends in food portion sizes, 1977-1998. JAMA 289, 450-453.

20. Ballard-Barbash R, Graubard I, Krebs-Smith SM et al. (1996) Contribution of dieting to the inverse association between energy intake and body mass index. Eur J Clin Nutr $\mathbf{5 0}$, 98-106.

21. Croft JB, Strogatz DS, James SA et al. (1992) Socioeconomic and behavioral correlates of body mass index in black adults: the Pitt County Study. Am J Public Health 82, 821-826.

22. Mertz W, Tsui JC, Judd JT et al. (1991) What are people really eating? The relation between energy intake derived from estimated diet records and intake determined to maintain body weight. Am J Clin Nutr 54, 291-295.

23. Kromhout D (1983) Energy and macronutrient intake in lean and obese middle-aged men (the Zutphen Study). Am J Clin Nutr 37, 295-299.

24. Romieu I, Willett WC, Stampfer MJ et al. (1988) Energy intake and other determinants of relative weight. Am J Clin Nutr 47, 406-412.

25. Satia-Abouta J, Patterson RE, Schiller RN et al. (2002) Energy from fat is associated with obesity in US men: results from the Prostate Cancer Prevention Trial. Prev Med 34, 493-501.

26. Institute of Medicine (2002) Dietary Reference Intakes for Energy, Carbohydrate, Fiber, Fat, Fatty Acids, Cholesterol, Protein, and Amino Acids. Washington, DC: National Academies Press.

27. Schoeller DA \& Fjeld CR (1991) Human energy metabolism: what have we learned from the doubly labeled water method? Annu Rev Nutr 11, 355-373.

28. Feinman RD \& Fine EJ (2004) 'A calorie is a calorie' violates the second law of thermodynamics. Nutr J3, 9.

29. Briefel RR, Sempos CT, McDowell MA et al. (1997) Dietary methods research in the third National Health and Nutrition Examination Survey: underreporting of energy intake. $\mathrm{Am} \mathrm{J}$ Clin Nutr 65, 4 Suppl., 1203S-1209S.

30. Moshfegh AJ, Rhodes DG, Baer DJ et al. (2008) The US Department of Agriculture Automated Multiple-Pass Method reduces bias in the collection of energy intakes. Am J Clin Nutr 88, 324-332.

31. Randi G, Pelucchi C, Gallus S et al. (2007) Lipid, protein and carbohydrate intake in relation to body mass index: an Italian study. Public Health Nutr 10, 306-310. 
32. Trichopoulou A, Gnardellis C, Benetou V et al. (2002) Lipid, protein and carbohydrate intake in relation to body mass index. Eur J Clin Nutr 56, 37-43.

33. Bowman SA \& Spence JT (2002) A comparison of low-carbohydrate vs. high-carbohydrate diets: energy restriction, nutrient quality and correlation to body mass index. J Am Coll Nutr 21, 268-274.

34. McAuley KA, Hopkins CM, Smith KJ et al. (2005) Comparison of high-fat and high-protein diets with a high-carbohydrate diet in insulin-resistant obese women. Diabetologia 48, 8-16.

35. McAuley KA, Smith KJ, Taylor RW et al. (2006) Long-term effects of popular dietary approaches on weight loss and features of insulin resistance. Int J Obes (Lond) 30, 342-349.
36. Hobbs F \& Stoops N (2002) Demographic Trends in the 20th Century. US Census Bureau, Census 2000 Special Reports, Series no. CENSR-4. Washington, DC: US Government Printing Office.

37. Flegal KM, Carroll MD, Kuczmarski RJ et al. (1998) Overweight and obesity in the United States: prevalence and trends, 1960-1994. Int J Obes Relat Metab Disord 22, $39-47$.

38. Flegal KM, Carroll MD, Ogden CL et al. (2010) Prevalence and trends in obesity among US adults, 1999-2008. JAMA 303, 235-241.

39. Wright JD, Borrud LG, McDowell MA et al. (2007) Nutrition assessment in the National Health And Nutrition Examination Survey 1999-2002. J Am Diet Assoc 107, 822-829. 